\section{AB0759 BIOLOGICS IMPROVES ARTERIAL STIFFNESS WITH CS DMARDS-RESISTANT ACTIVE PSORIATIC ARTHRITIS. A COHORT STUDY}

Kensuke Kume $^{1,2}$, Kanzo Amano $^{3}$, Toshikatsu Kanazawa ${ }^{3}$, Kazuhiko Hatta $^{3}$, Naohiko Matsumoto $2 .{ }^{1}$ Hiroshima Clinic, rheumatology, Hiroshima, Japan; ${ }^{2}$ Hiroshima Clinic, medical research, Hiroshima, Japan; ${ }^{3}$ Hiroshima Clinic, rheumatology, Hiroshima, Japan

Background: Patients with psoriatic arthritis (PsA) have an increased cardiovascular $(\mathrm{CV})$ risk. We should have strategies for primary cardiovascular prevention in $\mathrm{PSA}^{1)}$. But there is no evidence of $\mathrm{CV}$ risk management and arterial stiffness about biologics in patients with PsA Objectives: To examine the effect of biologics plus conventional synthetic (cs) DMARDs on arterial stiffness in cs DMARDs resistant PsA patients in a cohort study design.

Methods: 38 PSA and patients with moderate to severe active disease despite CS DMARDs treatment (disease activity score: DAPSA ${ }^{2)}$ score $>14$ ) were received Biologics plus cs DMARDs. All patients have no previous history of CV. Arterial stiffness was assessed with cardio-ankle vascular index (CAVI, modified pulse wave velocity(PWV)) and augmentation index corrected for a heart rate of 75 beats per minute (Alx@75) at baseline and 24 weeks follow-up. Clinical data were collected at regular visits. CAVI is very similar to pulse wave velocity (PWV), and CAVI measures arterial wall stiffness independent of blood pressure and it is superior to brachial ankle PWV as an index of arterial stiffness ${ }^{2}$.

Results: 35 PsA patients(18 patients adalimumab,13 patients infliximab, and 4 patients ustekinumab, respectively) completed this study, Treatment with biologics $(10.88 \pm 1.86$ and $9.46 \pm 1.14 \% ; p=0.006)$, attenuated the CAVI significantly from baseline to 24 weeks follow up. Treatment with biologics (36.4 \pm 8.6, $32.1 \pm 3.8 \% ; p=0.008)$ attenuated the Aix@75 significantly from baseline to 24 weeks follow up. DAPSA score improved significantly from baseline to 24 weeks $(17.45 \pm 6.33,5.44 \pm 3.43: p=0.01)$. There are no significant differences among biologics about CAVI and Aix@75. Surprisingly, improvement of CAVI and Alx@75 were not correlated disease activity at 24 weeks of biologics treatment (CAVI: $p=0.91$, Alx@75: $p=0.88$ ). Biologics improves arterial stiffness independently of its effects on disease activity, since even in high disease activity (4 cases; DAPSA score>28) is halted. Conclusion: These findings suggest that combination therapy, biologics with cs DMARDs not only reduced PsA disease activity but also limited vascular damage in patients with cs DMARDS resistant active PsA

\section{REFERENCES}

[1] Søren Lund Kristensen, et al. Psoriasis, psoriatic arthritis and cardiovascular risk: are we closer to a clinical recommendation? Ann Rheum Dis. 2015; 74: 321-2.

[2] Schoels MM, et al. Disease activity in psoriatic arthritis (PsA): defining remission and treatment success using the DAPSA score. Ann Rheum Dis, 2016; 75: 811-8.

Acknowledgement: Thank you for all paitents and colleagues. Disclosure of Interests: None declared DOI: 10.1136/annrheumdis-2019-eular.839

\section{AB0760 DRUG SURVIVAL AND EFFICACY OF USTEKINUMAB AND SECUKINUMAB IN PSORIATIC ARTHRITIS: A REAL- WORLD MULTICENTRIC COHORT OF 186 PATIENTS}

${ }^{1}$ Jean-Guillaume Letarouilly", Jeremie Sellam², Pascal Richette ${ }^{3}$, Philippe Dieudé ${ }^{4}$, Pascal Claudepierre $^{5}$, Corinne Miceli Richard ${ }^{6}$, Eric Houvenagel ${ }^{7}$, Chi Duc Nguyen ${ }^{8}$, Marie-Hélène Guyot ${ }^{9}$, Nicolas Segaud ${ }^{10}$, Laurent Marguerie ${ }^{11}$, Xavier Deprez ${ }^{12}$, Jean-Hugues Salmon ${ }^{13}$, Guy Baudens ${ }^{14}$, Maeva Kyheng ${ }^{15}$, Julien Paccou ${ }^{1}$, Elisabeth Gervais ${ }^{16}$, René-Marc Flipo ${ }^{1} .{ }^{1}$ Lille University Hospital, Rheumatology, Lille, France; ${ }^{2}$ Saint-Antoine University Hospital, Rheumatology, Paris, France; ${ }^{3}$ Lariboisière University Hospital, Rheumatology, Paris, France; ${ }^{4}$ Bichat University Hospital, Rheumatology, Paris, France; ${ }^{5}$ Henri Mondor University Hospital, Rheumatology, Créteil, France; ${ }^{6}$ Cochin University Hospital, Rheumatology, Paris, France; ${ }^{7}$ Saint-Philibert Hospital, Rheumatology, Lomme, France; ${ }^{8}$ Béthune Hospital, Rheumatology, Béthune, France; ${ }^{9}$ Roubaix Hospital, Internal medicine, Roubaix, France; ${ }^{10}$ Armentières Hospital, Internal Medicine, Armentières, France; ${ }^{11} \mathrm{Calot}$ Institute, Rheumatology, Berck-sur-mer, France; ${ }^{12}$ Valenciennes Hospital, Rheumatology, Valenciennes, France; ${ }^{13}$ Reims University Hospital, Rheumatology, Reims, France ${ }^{14}$ Rheumatology, Private Practice, Valenciennes, France; ${ }^{15}$ Lille University Hospital, MethodologyBiostatistics and Date Managment Department, Lille, France; ${ }^{16}$ Poitiers University Hospital, Rheumatology, Poitiers, France
Background: Ustekinumab (UST) and secukinumab (SEK) are new Biologic Disease-modifying AntiRheumatic Drugs (bDMARDs) available in psoriatic arthritis (PsA), targeting respectively IL12-23 and IL 17. Realworld data are missing for these drugs, despite the wide use. There is only one previous published study including 160 patients (1) receiving UST, but not SEK.

Objectives: To evaluate the characteristics of the patients with PsA treated by UST or SEK and to assess real life drug survival and efficacy of UST and SEK in PSA.

Methods: This is a national, retrospective, multicentric study from patients suffering from PsA (CASPAR criteria) from July 2011 to April 2018. Drug survival was defined as the time from initiation to discontinuation (stop/switch) of bDMARDs. Kaplan-Meier survival curves and Coxregression analyses [hazard ratios (HR) and 95\% confidence intervals (Cls)] were used adjusting for patient demographics, disease characteristics, co-therapy with methotrexate, and line of treatment with ustekinumab. For peripheral involvement, treatment was considered to be effective for patients with a combined favorable expert opinion and/or > $30 \%$ clinical improvement of swollen and tender joint counts. For axial involvement, efficacy criteria were: improvement of BASDAl by at least 2 points on a scale from 0 to 10 or $50 \%$ improvement and/or expert opinion.

Results: 186 patients were included with a mean follow-up $\geq 6$ months: 111 patients under UST and 75 under SEK. The mean age was 51.5 (12.9) years old, $55 \%$ of patients were women and the body mass index was 27.3 (5.8) $\mathrm{kg} / \mathrm{m}^{2}$. The disease duration was 10.8 (8.1) years Patients were bDMARDs-naïve in $15 \%$. The median drug survivals for UST and SEK were respectively 12 and 14 months (Fig1). A propensity score cannot be used to compare the two bDMARDs, since the number of patients was too small. Smoking was associated with an unfavourable drug survival for SEK (HR=0.22, 95\% Cl 0.91), whereas CRP levels were associated with a favorable one for UST (HR=1.009, $95 \% \mathrm{Cl} 1.003-$ 1.016). Nine patients under SEK and 2 under UST stopped their treatments due to side effects.

Conclusion: This is the first real-world study for drug survival on PsA for SEK and one with the largest number of patients for UST. Drug survival of UST and SEK seems similar to TNF inhibitors' (2).

\section{REFERENCES}

[1] lannone $F$, et al. Drug survival and effectiveness of ustekinumab in patients with psoriatic arthritis. Real-life data from the biologic Apulian registry (BIOPURE). Clin Rheumatol. 2018;37:667-75.

[2] Walsh JA, et al. Care Spec Pharm. 2018;24:623-631
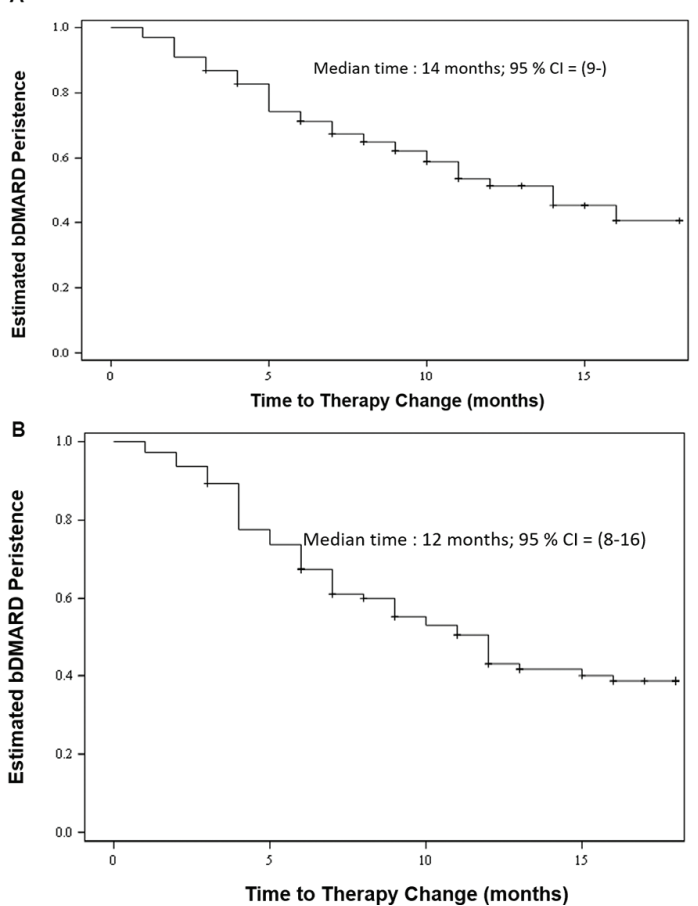

Abstract AB0760 Figure 1. Drug survival of secukinumab (A) and ustekinumab (B) in psoriatic arthritis 
Disclosure of Interests: Jean-Guillaume Letarouilly: None declared, Jeremie Sellam: None declared, Pascal Richette Consultant for: Grunenthal, Horizon, Speakers bureau: AstraZeneca, Grunenthal, Philippe Dieudé: None declared, Pascal Claudepierre Consultant for: Honoraria from Novartis as steering committe of this survey, Corinne Miceli Richard Grant/ research support from: MSD, Pfizer, AbbVie, Biogen, UCB, Novartis, Consultant for: Abbvie, Novartis, BMS, Eric Houvenagel Speakers bureau: Lilly, Novartis, Janssen, Chi Duc Nguyen: None declared, Marie-Hélène Guyot: None declared, Nicolas Segaud: None declared, Laurent Marguerie: None declared, Xavier Deprez Speakers bureau: Novartis Janssen, Jean-Hugues Salmon Speakers bureau: Janssen Novartis, Guy Baudens Grant/research support from: Financial Grant from NordicPharma, Consultant for: Roche SAS, Maeva Kyheng: None declared, Julien Paccou Speakers bureau: Novartis Janssen, Elisabeth Gervais Grant/research support from: Roche, Pfizer, Consultant for: Bristol-Myers Squibb, UCB, René-Marc Flipo Consultant for: Honoraria from Novartis as steering committe of this survey

DOI: 10.1136/annrheumdis-2019-eular.3279

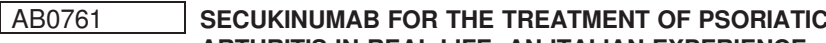 ARTHRITIS IN REAL LIFE: AN ITALIAN EXPERIENCE}

${ }^{1}$ Federica Martinis ${ }^{*}$, Cristian Caimmi ${ }^{1}$, Rosario Foti ${ }^{2}$, Elisa Visalli ${ }^{2}$, Giorgio Amato ${ }^{2}$, Roberta Ramonda ${ }^{3}$, Augusta Ortolan ${ }^{3}$, Mariagrazia Lorenzin ${ }^{3}$, Angelo Semeraro ${ }^{4}$, Leonardo Santo ${ }^{5}$, Emanuela Praino ${ }^{5}$, Maria Sole Chimenti ${ }^{6}$, Roberto Perricone ${ }^{6}$, Favia Sunzini ${ }^{6}$, Raffaele Scarpa ${ }^{7}$, Francesco Caso ${ }^{7}$, Luisa Costa ${ }^{7}$,

Elena Fracassi ${ }^{1}$, Maurizio Rossini ${ }^{1}$, Antonio Carletto ${ }^{1} .{ }^{1}$ Rheumatology Unit, University of Verona, Verona, Italy, ${ }^{2}$ Rheumatology Unit, A.O.U. Policlinico Vittorio Emanuele, Catania, Italy, ${ }^{3}$ Rheumatology Unit Department of Medicine, DIMED, University of Padova, Padova, Italy; ${ }^{4}$ Rheumatology Unit, ASL Taranto, Taranto, Italy; ${ }^{5}$ Rheumatology Unit, ASL BT Andria - DSS4 Barletta, Italy, Barletta-AndriaTrani, Italy; ${ }^{6}$ Rheumatology, allergology and clinical immunology, University of Rome Tor Vergata, Roma, Italy, ${ }^{7}$ Rheumatology Unit, Department of Clinical Medicine and Surgery, University Federico II, Napoli, Italy

Background: Secukinumab is a novel treatment for psoriatic arthritis (PsA) but data from real life are still missing.

Objectives: The aim of this study is to evaluate a wide cohort of PsA patients on secukinumab followed in 7 Italian rheumatologic centers. Methods: Two-hundred and seventy-nine patients affected by PsA and on secukinumab were enrolled. Data on disease characteristics, previous and ongoing treatments, comorbidities and duration of follow-up were collected. In particular DAPSA and ASDAS were used to assess articular and axial disease activity.

Results: Mean age of our cohort was $53 \pm 11$ years and BMI $26.4 \pm 5.1 \mathrm{~kg}$ $\mathrm{Im}^{2}$ with the majority of patients being female (63.8\%). Mean disease duration was $9.7 \pm 7.5$ years and mean follow-up was $10.9 \pm 6.8$ years. For 100 patients $(35.8 \%)$ secukinumab was their first line biologic treatment and $41(50.5 \%)$ were in monotherapy. DAPSA was $25.9 \pm 10.5$ at baseline, $15.9 \pm 9.7$ at $M 3,12.9 \pm 8.4$ at $M 6,9.8 \pm 7.1$ at $M 12$ with a significant downward decrease at every visit as compared to baseline $(p<0.001$ for each comparison to baseline). ASDAS at baseline was $3.27 \pm 1.15,2.32 \pm 0.99$ at $\mathrm{M} 3,2.04 \pm 1.12$ at $\mathrm{M} 6,1.96 \pm 0.88$ at $\mathrm{M} 12$ with a significant downward decrease at $M 3$ and $M 6 \quad(p<0.001)$ and a downward trend for $M 12$ $(p=0.064)$, probably because of the small number of patients with axial involvement at $\mathrm{M} 12$ (15). After 12 months of treatment $70.6 \%$ with axial involvement and $76.6 \%$ with articular manifestations had an inactive diseasellow disease activity, accordingly to ASDAS and DAPSA respectively. Forty patients $(14.3 \%)$ stopped the treatment during the follow up mainly because of primary or secondary loss of efficacy (18 and 10, respectively). Only 9 patients suspended the treatment because of adverse events, of which 5 because of reactions at site of injection.

The retention rate at 12 months was very good in the whole population (figure), and in particular in patients with entesitis at the baseline (10.5 vs, 11.2, $\mathrm{p}=0.038$ ). No differences in survival were found when dividing patients accordingly to $\mathrm{BMl}$, although overweight or obese patients showed a trend for a better retention rate (10.6 vs $10.9, \mathrm{p}=0.089)$. Interestingly no differences were found between naïve and non-naïve patients $(p=0.895)$ and between those in monotherapy or in combination therapy $(\mathrm{p}=0.925)$.

Conclusion: This is one of the first real life studies on secukinumab and shows a very good efficacy and safety of this treatment in PsA patients, also for the articular manifestations, as shown by a significant decrease of DAPSA over a 12-months follow up.

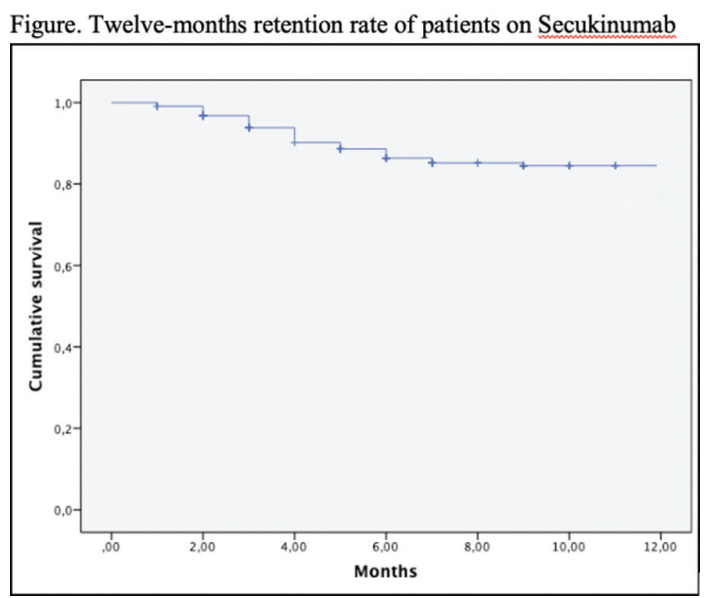

Disclosure of Interests: Federica Martinis: None declared, Cristian Caimmi: None declared, Rosario Foti: None declared, Elisa Visalli: None declared, Giorgio Amato: None declared, Roberta Ramonda: None declared, Augusta Ortolan: None declared, Mariagrazia Lorenzin: None declared, Angelo Semeraro: None declared, Leonardo Santo: None declared, Emanuela Praino: None declared, Maria Sole Chimenti: None declared, Roberto Perricone: None declared, Favia Sunzini: None declared, Raffaele Scarpa: None declared, Francesco Caso: None declared, Luisa Costa: None declared, Elena Fracassi Speakers bureau: Novartis, Maurizio Rossini: None declared, Antonio Carletto Speakers bureau: Roche, Novartis, MSD, Abbvie, Bristol, Jannsen, Celgene, Pfizer

DOI: 10.1136/annrheumdis-2019-eular.5443

\section{AB0762 TREATMENT WITH TOFACITINIB IN REFRACTORY PSORIATIC ARTHRITIS. MULTICENTER STUDY OF CLINICAL PRACTICE}

${ }^{1} J o s e ́$ Luis Martín-Varillas", Eva Galindez ${ }^{2}$, Esteban Rubio Romero ${ }^{3}$, Agusti SellasFernández ${ }^{4}$, Roberto Daniel Gonzalez Benitez ${ }^{5}$,Beatriz Joven-lbáñez ${ }^{6}$, José Campos Esteban ${ }^{7}$, Olga Rusinovich ${ }^{7}$, Vanesa Calvo-Río ${ }^{1}$, Francisco OrtizSanjuán $^{8}$, Clara Ventín-Rodríguez ${ }^{9}$, Luis Fernández-Dominguez ${ }^{10}$, Antia Crespo Golmar ${ }^{11}$, Ximena Elizabeth Larco Rojas ${ }^{11}$, Manuel Moreno ${ }^{12}$, Alejandro Escudero Contreras ${ }^{13}$, Emma Beltrán $^{14}$, Rafael Melero ${ }^{15}$, Maria Jose Moreno ${ }^{16}$, Enrique Raya ${ }^{17}$, Beatriz Arca ${ }^{18}$, María-Luisa Peral ${ }^{19}$, Olga Maiz ${ }^{20}$, Raul Veroz Gonzalez ${ }^{21}$, Alfonso Corrales ${ }^{1}$, Natalia Palmou-Fontana ${ }^{1}$, Belén AtienzaMateo $^{1}$, J. Loricera ${ }^{1}$, Miguel A. González-Gay ${ }^{1}$, Ricardo Blanco ${ }^{1} .{ }^{1}$ H.U.M. Valdecilla, Santander, Spain; ${ }^{2} \mathrm{H}$. Basurto, Bilbao, Spain; ${ }^{3} \mathrm{H}$. Virgen del Rocío., Sevilla, Spain; ${ }^{4}$ H. Vall d'Hebron, Barcelona, Spain; ${ }^{5}$ H.G.U. Gregorio Marañón, Madrid, Spain; ${ }^{6} \mathrm{H} .12$ de Octubre, Madrid, Spain; ${ }^{7}$ H. Puerta de Hierro, Madrid, Spain; ${ }^{8} \mathrm{H}$. La Fe, Valencia, Spain; ${ }^{9} \mathrm{H}$.U. A Coruña, A Coruña, Spain; ${ }^{10} \mathrm{H}$. Ourense, Ourense, Spain; ${ }^{11} \mathrm{H}$. León, León, Spain; ${ }^{12} \mathrm{H}$. Virgen Arrixaca, Murcia, Spain; ${ }^{13} \mathrm{H}$. Reina Sofia, Córdoba, Spain; ${ }^{14} \mathrm{H}$. del Mar, Barcelona, Spain; ${ }^{15} \mathrm{H}$. Vigo, Vigo, Spain; ${ }^{16} \mathrm{H}$. Rafael Méndez, Lorca, Spain; ${ }^{17} \mathrm{H}$. San Cecilio, Granada, Spain; ${ }^{18} \mathrm{H}$. San Agustín, Avilés, Spain; ${ }^{19} \mathrm{H}$.G.U. Alicante, Alicante, Spain; ${ }^{20} \mathrm{H}$. Donosti, San Sebastián, Spain; ${ }^{21} H$. Mérida, Mérida, Spain

Background: Tofacitinib (TOFA) is the first inhibitor of JAK kinases with approval for the treatment of psoriatic arthritis (PsA) in Europe (July 2018) ${ }^{1}$. TOFA has shown efficacy in refractory patients to anti-TNF ${ }^{2}$.

Objectives: A) to assess efficacy and safety of TOFA in the first cases in Spain in clinical practice. B) to compare the profile of clinical practice patients with clinical trial.

Methods: Study of 41 patients of clinical practice with PsA treated with TOFA in Spain. The diagnosis of PSA was made using CASPAR criteria. Patients who received at least one dose of TOFA were included. Results are expressed as percentage, mean $\pm S D$ or median [IRQ]

Results: 41 patients $\left(23+180^{7}\right)$, mean age of $50.2 \pm 10.7$ years (table 1 ). Pattern joint involvement was as follows: peripheral $(n=25)$, axial (1) and mixed (15). During the PsA evolution, in addition to arthritis, patients also presented enthesitis (60.9\%), nail involvement $(39 \%)$ and dactylitis (31.7\%). 